\title{
New directions in the development of neuromarketing and behavioral economics
}

\author{
Andrey Plakhin ${ }^{1 *}$, Igor Semenets ${ }^{2}$, Ekaterina Ogorodnikova ${ }^{1}$ and Maria Khudanina $^{1}$ \\ ${ }^{1}$ Ural State University of Economics, Department of Management, 8th March str. 62, Ekaterinburg, Russian Federation \\ ${ }^{2}$ Slavonic University of the Republic of Moldova, Department of Economics, Florilor str. 28/1, Chisinau, Moldova
}

\begin{abstract}
The article substantiates the relevance of neuromarketing studies based on an understanding of the basic functional mechanisms of the consumer's nervous system. Such studies include high-precision hardware testing of unconscious human responses to audio-visual or any other stimulus. Neuromarketing is considered as a symbiosis of separate disciplines: psychology and psychophysiology, traditional marketing and economics, neurobiology, econometrics, etc. In the work comparison with traditional marketing researches on such parameters as: objectivity of an estimation of results received during researches is made; also effectiveness of application in practices was investigated; sample for the study is selected; cost of research and interpretation of results are determined. The foreign experience of using neuromarketing technologies and behavioural economics on the example of such organizations as Singapore Airlines, Nike, Starbucks, automotive companies, universities, etc. was studied. Comparison with the Russian level of development of innovative marketing is made. Recommendations are given on the introduction of neuromarketing in the Russian automotive industry using the example of AvtoVAZ. The efficiency and value of carrying out neuromarketing research in the enterprise and the possible economic effect are calculated. The main tasks of modern higher education are marked and innovations in the learning process are proposed.
\end{abstract}

\section{Introduction}

In modern microeconomics, presumably, there is no marketer who does not set a goal to correlate the product with the buyer and give people what they really want most. Today it is not enough to understand and manage price policy: it is absolutely necessary to know the nature of a person, including his emotions. This is important, as the consumer becomes more demanding and sophisticated, complicating behaviour patterns. He understands that the product is not only a collection of consumer properties and services, but it is both emotions and feelings that appear when buying and using. It is the emotional processes and thoughts associated with branding that are the predominant reactions to product quality [1]. To understand such reactions, neuromarketing research is carried out, which today no longer has a creative solution, but a rational approach [2], [3].

In this article, the authors tried to characterize neuromarketing, its goals and objectives, as well as involvement in the behavioural economy. The advantages and disadvantages of technologies that help to compare neurovisualization with the tools of traditional marketing are considered. Further, the importance of categories such as emotions, motivational structure and cognitive distortions of a person is indicated. In the first part, you can find out what categories they are and why it is so important to consider them when forming a commercial offer. Then the analysis of other channels of influence on the consumer is presented: various forms of visual representation of a product or service, their tangible features, musical and aromatic support.

In the second part, foreign experience of introducing neuromarketing technologies, features and structure of innovations in European companies are considered. Comparative statistics are presented, which shows a relatively low level of development of marketing, including neuromarketing, innovations in Russia [4].

At the end of the article, a conclusion is drawn that neuroimaging in Russian organizations can be applied regardless of the scope and type of activity. In particular, in the automotive industry or education.

\section{Theoretical aspects of neuromarketing}

\subsection{Content and objectives of neuromarketing research}

Neuromarketing is a new direction in marketing, which uses brain research - neuroimaging - to study the behaviour of the buyer. In fact, this is one of the tools of the customer relationship management (CRM), built on the basis of understanding the fundamental functional mechanisms of the nervous system. It includes highprecision hardware testing of unconscious human responses to audio-visual or any other stimulus. Such irritant can be advertising, label or packaging, particularly

\footnotetext{
Corresponding author: apla@,usue.ru
} 
a product or service. Knowledge of how irritants affect the main 4 channels of communication: hearing, sight, touch and smell through consciousness, make it possible to analyse the behaviour of consumers, change their thoughts even before understanding and making a choice [5].

At the same time, it should be noted that, according to the Russian Federal Law on Advertising No. 38-FZ of 13 March 2006, Article 9 [6] states: "Radio, television, video, audio and film products or other products shall not be used and distributed hidden advertising, that is, advertising, which has an impact on their consciousness not realized by consumers of advertising...". Therefore, neuromarketers should not pursue the goal of deceiving or imposing an unnecessary product on the buyer, but they can investigate their attention and reaction to the advertised product for the most effective promotion [7]. Thus, neuromarketing can be described as an interdisciplinary science, since the development of events uses already accumulated or acquired knowledge from psychology and psychophysiology, neurobiology, traditional marketing, neuroeconomics, economics and econometrics and other branches of knowledge.

The combination of all these sciences provides an opportunity for a fuller and deeper understanding and classification of the buyers value system, the structure of their motivation, correcting socially directed and lifeaffirming factors of self-perception and self-esteem.

All these factors can be expressed in the exact price positioning, or in the development of precisely those products that will be more in demand by the potential consumer (both because of the presence of specific physical characteristics in this product, and because of some emotional attractiveness not reducible to operationalization) or in the ability to communicate accurately with their customers, or in the optimal layout of retail space, or in maximizing product life cycle and brands themselves.

Therefore, we can identify the following main tasks of neuromarketing:

1. In the paper "Neuromarketing: Myths, Real Goals and Traps" [8] Oleg Klepnikov and Maria Chernova compare neuromarketers with artists: they combine a systematic approach and an uncontrollable subconscious process. In the case of neuromarketing, it is necessary to combine all theoretical and empirical knowledge of traditional economic sciences with applied sciences and brain research and consumer behaviour.

2. Neuromarketers in the course of experimental and scientific activity determine the reasons and sequence of making decisions about the purchase or refusal of a particular product.

3. Nomination of the most logical ways, or in some cases illogical, for promotion of goods in accordance with the true needs of the potential buyer, identified in the course of research. The development of such strategies for places of sale, which would fall into the focus of selective (selective) customer perception.

In this case, in our opinion, it is not necessary to resort to "ultrasound" brain activity every time: it is enough to interpret the buyer's reaction with the help of a number of the above-named disciplines and experiments that confirm this interpretation.

\subsection{Advantages and disadvantages of neuromarketing: comparison with traditional methods}

Analysis of literature sources allows to formulate the following main advantages of neuromarketing in comparison with traditional marketing research, and some disadvantages of neuromarketing technologies. Let us also consider which of the shortcomings are more or less justified.

The most important privilege is an objective evaluation of the subjective reaction of a person to a product or service, or their component. Possession of such information can give an advantage in the form of influence on purchasing behavior so that the costs of conducting neurovisualization studies will be justified and paid off by improving the product and increasing sales.

It has been proven that neuromarketing technologies provide marketers with information that can not be obtained through conventional marketing methods. According to experts, $95 \%$ of all thoughts occur in our subconscious, and it is these data that can not be fully obtained through surveys or focus groups, and some of them can be misinterpreted.

Let's look at an example. Baileys liqueur and Red Bull drink did not like the focus groups at the initial stages, and according to preliminary tests it was revealed that the subjects did not even agree to try the drinks more at all. However, the products were brought to the market, and now it is sold superbly throughout the world [9].

No less important is that the results of many neuromarketing research are now available to a wide range of people. This means the applicability of such data in building a development strategy and planning sales not only in large companies, but also in small and mediumsized businesses. It is the society that makes information open: we have moved to the digital level and every day we are creating a huge amount of archival data.

On the other hand, there arises the problem of protecting the privacy of clients. This, as well as the desire to keep secret the interpretation of the data, does not allow some companies to publish the results of the conducted studies. Nevertheless, although some of the information remains open, the tools for its analysis remain closed [10].

Another disadvantage is the inadequate sample in the studies. Back in 1979, the work of Amos Tversky and Daniel Kahneman "Prospect Theory: An Analysis of Decision under Risk " was published [11], in which it was demonstrated how strongly economic theories differ from people's behavior in real life. Today, a whole science has emerged about the description of the behavior of buyers the behavioral economy - which is scientifically supported by neuromarketing. Although it was previously thought that the error factor in decision-making can not be predicted, according to the work of Tversky and Kahneman, economic rationality is systematically violated, but errors in decision making are not only widespread, but also predictable [12]. 
This is partly written about by Dan Ariely in his book "Predictable Irrationality" [12]. Therefore, it can be stated that this is one of the reasons why a large sample should not become a decisive factor when choosing a method of marketing research.

The second reason speaks for itself: the Nielsen company conducted an experiment that showed that the neurosearch for a sample of 100 people gives the same result as for a sample of 20 people [13].

Further, according to the generally accepted opinion, and this is the strongest "anti-stimulus", neuromarketing technologies are one of the most expensive methods of research.

Thus, the scientific direction in marketing analysis gives an answer to the question what the consumer really needs, and how to sell him a "useful" product. Neuromarketing can be characterized as an accessible method of research and promotion of goods, and effective and wearing an objective shade.

\section{Russian and foreign experience of using neuromarketing technologies and behavioural economy}

To date, there are some more than 250 research centres around the world dealing with neuromarketing. There is also an opportunity to pass special educational courses on neuromarketing in such universities as "Erasmus University of Rotterdam" (Netherlands), "INSEAD" (France), "Zeppelin" (Germany) and "Stanford" (USA) [14].

In the international arena, companies of various industries apply the behavioural economy in practice, including neuroimaging. Let's give some examples.

Sensual branding is used by "Singapore Airlines". The company enjoys a special colour scheme and the smell of "Stefan Floridian Waters", which is used by flight attendants. This smell is also impregnated with towels and other attributes on board.

"Starbucks" is asking for a high price not only for coffee, but also for a unique combination of interior design, exotic smells, background music from around the world. Constant neuromarketing research is conducted by "Nike". The company is well-oriented in the market due to the behavioural economy. More than 10 applications that track the overall physical condition of a person, allow consumers to add all the necessary information to a wellknown brand.

From the examples above, it can be seen that innovations can be introduced in various ways: with the use of special equipment, impact on sensorics or the development of applications; in all kinds of spheres and branches.

Most European companies already take into account behavioural patterns in their pricing policies and advertising, and traditional methods are inherent in organizations that have long held a stable position in the market due to the old technology of doing business or without growth tendencies.

Moreover, Russian companies are lagging behind the Western ones on the introduction of innovative technologies for about 2 to 3 years [15].
According to experts, in Russia people are more exposed to neuromarketing than Europeans. For example, from the use of sound, you can expect sales to increase by $10 \%$ in the West, while at the same time in the Russian company sales in this way are increased by a third [16].

According to studies of the European market of neuromarketing among countries in terms of the cost of neuromarketing activities confident leader is Germany, with a total amount of over 100 million USD per year. In Russia, the amount is about 3 times less (Fig. 1) [17]. 112808.8

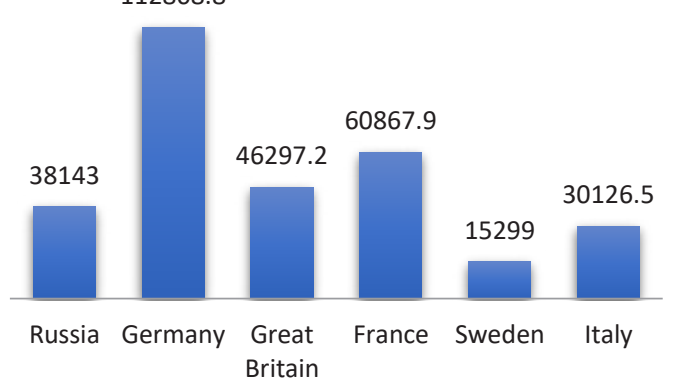

Fig. 1. Domestic expenditure on research and development, million US dollars

It is rather indicative also the analysis allowing to estimate a share of the companies on the countries which in one form or another apply marketing innovation tools in the activity (Fig. 2) [17].

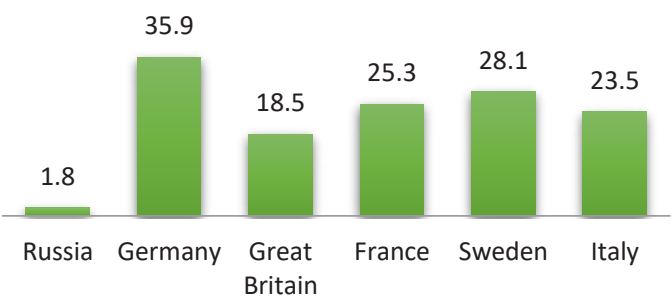

Fig. 2. Relative density of organizations using marketing innovations, $\%$

As the results of Agny's research show, in Russian companies the adoption of marketing decisions largely depends on the subjective opinion of specialists [17]. While it is clear that effective solutions can only be achieved through scientific evidence based on the use of innovation, including neuroimaging.

Certainly, some Russian companies have succeeded in conducting neuromarketing research and applying the behavioural economy in practice. The brain laboratory, NeuroTrend, OLYMPIA and other research centres offer to conduct neuroimaging and find out the true consumer preferences. In the process, many professional skills and knowledge are integrated. For example, in St. Petersburg, the leading doctors - psychotherapists, candidates of philological sciences, astronomers and even mentalists united in the promotion company. All this contributes to the effective and reasonable development of the brand. As for the direct application of the behavioural economy in practice, we can give an example of some companies that do not hide this information: Makfa, Uvelka, Borjomi, Cherkizovo, Faberlic, Sela, Dixi, leading Russian mobile operators, etc. As you can see, the largest companies preferred innovative technologies. 
Organizations that are not ready to widely modify and promote business, realize the need for neuroeconomics in B2B. For example, using an outsourcing call centre.

Obviously, in Russia it is necessary to develop neuromarketing and to identify new directions, where the use of the behavioural economy is necessary. Since in the global science the share of the Russian Federation is no more than $2 \%$, then efforts should focus on the introduction of innovations.

\section{New directions of neuromarketing development and behavioural economy in Russia}

\subsection{Car production}

The automotive industry in Russia is constantly changing and is facing a lot of different problems. One of the reasons for the backwardness of the industry is that enterprises pay insufficient attention to research and development. Let's consider in dynamics specific density of the organizations which are carrying out marketing innovations in the process of production of vehicles and equipment in their total number for 2009 - 2015 (Fig. 3) [8].

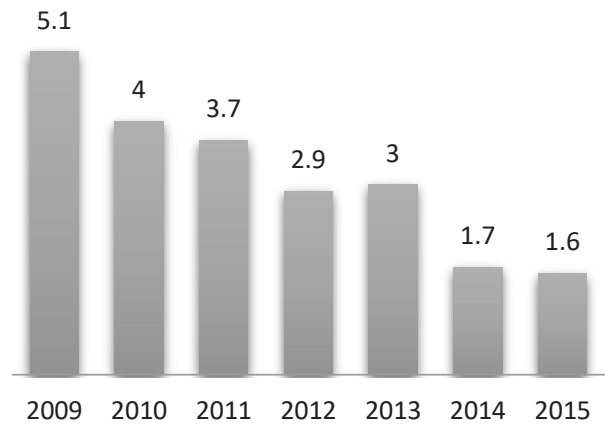

Fig. 3. Specific weight of organizations engaged in marketing innovations in the production of vehicles and equipment in the total number of organizations surveyed for 2009-2015,\%

As can be seen from the graph, every year the number of organizations implementing innovative marketing solutions is decreasing.

At the same time, a number of European automakers, systematically conducting neuromarketing research, can observe the following dynamics of profit growth (Fig. 4).

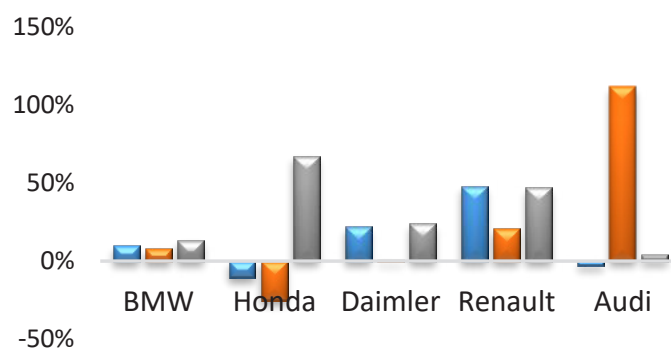

$\square 2015 \square 2016 \square 2017$

Fig. 4. The growth rate of net profit in 2015-2017 for companies with the practice of introducing neuromarketing
BMW uses the slogan created by neuromarketers: "The Ultimate Driving Machine", which focuses on the complex of pleasant experiences that the consumer will experience while driving. BMW, Honda and Audi also have their own fragrance, which is also an instrument of sensory influence on a person's consciousness. Daimler conducts research on the impact of the product on the consumer and develops special advertising campaigns; thanks to one of these advertising sales grew by $12 \%$, etc. In order to build a strategy for the development of production and sales, let us turn to the leading Eurasian automotive companies that have already introduced neuromarketing technologies, and advertising campaigns are built according to the canons of the behavioural economy.

Let's take AvtoVAZ as an example. AvtoVAZ is a Russian automotive company, the largest car manufacturer, with a market share of $19.5 \%$. In 2017 , $45 \%$ of cars were sold through state support programs. 17 new LADA auto centres were opened, and retail sales grew by $31 \%$ [18].

In 2016, the expenses of the auto concern for advertising increased 4-fold, and in 2017 they decreased 2-fold. Let's consider the marketing strategy of AvtoVAZ in more detail.

First, the Russian manufacturer is preparing in the next ten years the release of 12 completely new SUVs built on the platforms of the most popular cars.

Looking at this situation from the other side, it is appropriate to use the Zaltman metamorphism method (ZMET), widely used in neuromarketing and in the automotive industry, by the transnational automotive concern Daimler.

At the first stage of the target audience, it is suggested to select pictures reflecting the emotional state of each individual person. Pictures should encourage the creation of associative links with respect to any statements without direct binding. For example, pictures associated with investing or proper nutrition. Then the researcher conducts interviews with each participant within 1-2 hours.

In the process of research it is possible to reveal a latent reaction to a car, to uncover thoughts, feelings and desires about a product. These are deep processes of consciousness contained within the human mindset of people, and reactions to auditory, visual, kinaesthetic information or another stimulus. The result can be used when changing the shape, design, type, colour, quality of the upholstery material, etc.

The basis of the model is a symbiosis of neurobiology, psychoanalysis, psychology, art and theory to identify mental models that determine human behaviour and other sciences.

Thus, it is not necessary to change and adjust the autoconstruction completely to the European model, but to create one.

It is also appropriate to use such devices as EEG, eyetracking, polygraph and others. For example, the South Korean automotive company Hyundai used the EEG to test its prototypes. The activity of the brain was measured for various design features and it was studied what kind of stimulation is likely to lead to a purchase. The results 
of this study influenced the decision to change the exterior design of the cars themselves.

Secondly, an aggressive advertising campaign. Advertising war with AvtoVAZ is carried out by the largest car dealers Citroen, Audi, Volkswagen, Ford, Hyundai, who have long considered the behavioural economy.

Nevertheless, AvtoVAZ is also trying to affect emotion emotionally the consumer's consciousness using consonant associations in the advertising company to the Vesta model.

Since there are two ways of forming loyalty and "falling in love" with the consumer towards the manufacturer, it is probably worth paying attention not only to the emotional component, but also to cognitive distortions.

The idea is not to create and use distortions, but to develop critical thinking in favour of the Russian automotive industry.

For example, the binding heuristic (anchor effect). Consciously there is a binding to the European standards of automobile designs. People are ready to overpay for the brand and the framing it created. This is what we call "brand equity".

There are several ways to deal with a distorted consciousness: develop critical thinking and encourage the buyer to reassess values and views. The choice of a car can be caused by a "trap of incomplete information", when decision-making is based on a few unpleasant facts, while there are hundreds of them, and the consumer does not need to know anything more about them.

The easiest way to point people to their own mistakes is with the help of accurate measuring equipment: a lie detector, an MRI, etc.

Third, the development of e-commerce. With the advent of the new function of buying cars online, new prospects opened on the site of AvtoVAZ. Neuromarketing tools can be used in advertising texts and graphics, NLP; They can affect conversion and total sales.

We calculate the overall economic efficiency of the proposed innovations in AvtoVAZ.

First of all, we will list the activities and their cost characteristics for a sample of 200 to 1500 people, depending on the duration and quality of the event (Table $1)$.

Table 1. Proposed list of neuromarketing activities and their cost characteristics

\begin{tabular}{|l|c|}
\hline \multicolumn{1}{|c|}{ Neuromarketing event } & Cost characteristics \\
\hline $\begin{array}{l}\text { Conducting ZMET using additional } \\
\text { equipment: traditional marketing tools } \\
\text { and neuromarketing, including: EEG; } \\
\text { MRI; polygraph; eye-tracker }\end{array}$ & $\begin{array}{c}\text { From } 60,940 \\
\text { thousand rubles to } \\
110,750 \text { thousand } \\
\text { rubles }\end{array}$ \\
\cline { 1 - 2 } $\begin{array}{l}\text { Attraction of highly qualified personnel } \\
\text { for holding events }\end{array}$ & $\begin{array}{c}\text { The same costs as } \\
\text { with a traditional } \\
\text { advertising campaign } \\
\text { (from 1 to 2 billion } \\
\text { rubles.) }\end{array}$ \\
\hline $\begin{array}{ll}\text { Interpretation of resultsB } \\
\text { formation of a new heuristic binding an advertising campaign }\end{array}$ \\
\hline Development of commercial trade
\end{tabular}

Further, we will estimate the level of quality of neuromarketing research (Table 2).

Table 2. The system of indicators used in forecasting the correspondence of the results of the study with the objectives of the study

\begin{tabular}{|c|c|}
\hline Index & $\begin{array}{c}\text { Value and range of evaluation of } \\
\text { the study quality }\end{array}$ \\
\hline Deadlines & 6 months \\
\hline $\begin{array}{l}\text { The value of the results } \\
\text { (Table } 3 \text { ) }\end{array}$ & $\begin{array}{l}\text { Average level. Opens prospects of } \\
\text { the Russian car industry } \\
\text { development, increase in sales } \\
\text { volume, etc. }\end{array}$ \\
\hline Level of results novelty & Getting new results \\
\hline $\begin{array}{l}\text { Actuality and relevance } \\
\text { of the study }\end{array}$ & $\begin{array}{l}\text { The high significance of the } \\
\text { research, both from the point of } \\
\text { view of the automotive industry, and } \\
\text { in general of the economy in Russia }\end{array}$ \\
\hline $\begin{array}{l}\text { Possible scale of results } \\
\text { implementation }\end{array}$ & Branch \\
\hline $\begin{array}{c}\text { Technical and } \\
\text { methodological levels of } \\
\text { the study } \\
\end{array}$ & $\begin{array}{l}\text { Full compliance of the technical } \\
\text { means and techniques used with } \\
\text { modern achievements of science }\end{array}$ \\
\hline $\begin{array}{l}\text { Volumes of results } \\
\text { implementation }\end{array}$ & $\begin{array}{l}\text { Partial implementation of the results, } \\
\text { depending on the professionalism of } \\
\text { the researchers interpreting the } \\
\text { findings }\end{array}$ \\
\hline
\end{tabular}

Table 3. Evaluation of the effectiveness of information (by peer review).

\begin{tabular}{|c|c|}
\hline \multicolumn{2}{|c|}{$\begin{array}{l}K=f(i ; c ; d)=i * c * d=0,45 \\
\text { The average level of information value }\end{array}$} \\
\hline I & 0,5 \\
\hline $\mathrm{C}$ & 0,9 \\
\hline $\mathrm{D}$ & 1 \\
\hline
\end{tabular}

Based on the experience of foreign automotive companies and concerns, the introduction of neuromarketing research can increase profit growth up to $24 \%$ (Daimler). However, taking into account the average level of the value of information and the high cost of marketing research, experts predicted growth of the company until 2020, the average increase in profits of foreign companies, which arose through neuroimaging, the additional profits can be expected to increase to $10 \%$.

Given the above, it seems appropriate to consider the use of neuromarketing technologies in AvtoVAZ, as many European companies have already successfully implemented these innovations and were able to increase sales.

\subsection{Education and training of specialists}

Even today in Russia you can take courses in neuromarketing in major universities, namely the Moscow State University. Lomonosov, MGIMO, REU and some others.

At the same time, it is quite obvious that it is necessary to modernize the education system in the sphere of marketing.

The main tasks of modernization include:

- the flexibility and effectiveness of vocational training programs; 
- conformity of technologies used in training, the needs of modern economy;

- training of specialists who will later be engaged in research work.

Flexibility and effectiveness of training programs can be provided only through the introduction of modern disciplines. It is quite obvious that classical marketing does not allow us to examine the state of the market from all points of view. In this regard, it is advisable to allow students to assess the current status of enterprises with the help of tools of the behavioural economy, incl. neuroimaging.

Therefore, it is necessary to introduce neuromarketing tools into the learning process: methods, work with equipment, methods of interpretation of data; To improve skills and disseminate knowledge about innovations among students and listeners. Influence emotions and motivational structure.

Thus, it is possible to train more researchers and specialists in non-traditional marketing, to develop more capacious and effective training programs. This will increase the economy of the state as a whole, conduct effective sales and conduct successful advertising campaigns, reducing the budget for expenses to obtain unreliable information.

Neuromarketing technologies have the potential to conquer the Russian market. Neuroimaging makes it possible to deeply understand such questions as the motivational structure of the consumer, his values and gives opportunities for segmentation at a qualitatively new level. It has a wide scope for application both in manufacturing, retail trade, and education.

\section{References}

1. P. Bardeen, Hacking Marketing. 97-110 (2014).

2. R. Dooly, Neuromarketing. How to influence the subconsciousness of the consumer. 59-69 (2018).

3. D. Lewis, Neuromarketing in action. How to penetrate the buyer's brain. 40-51, 113-115 (2015).
4. E.V. Avdeychikova, S.P. Trubitsyna, V.V. Burgat, Innovations in trading activities: Russian and foreign experience. Moscow. 140-148 (2016).

5. E. Sternberg, Neurologics: What explains the strange things that we do unexpectedly for ourselves 302 313, 315-320 (2017).

6. On advertising: Federal Law No. 38-FZ of March 13, 2006 (as amended on December 31, 2017).

7. M. Akulich, Neuromarketing. Publishing Solutions. 30-31, 46-48, 143-150 (2018).

8. M.A. Chernova, O.E. Klepikov, Neuromarketing: myths, real goals and traps, available at: http://www.marketing.spb.ru/libaround/science/neuromarketing.htm (accessed 07/04/2018).

9. RBC Magazine: research and market news. available at: http://marketing.rbc.ru/ (accessed 07/04/2018).

10. Lada.online, available at: http: //lada.online.ru/ (accessed 07/04/2018).

11. D. Kahneman, A. Tversky. Prospect Theory: An Analysis of Decision under Risk. Econometrica (1979).

12. D. Ariely, Predictable irrationality. 166-170, 172-180 (2008).

13. R. Thaler, New behavioral economics. 66-69 (2017).

14. W. Davis, The industry of happiness. 245-261 (2017).

15. Adview: Using neuromarketing to increase sales, available at: http: //adview.ru/ (accessed 07/04/2018).

16. Rosstat: state statistics, available at: http://gks.ru/ (accessed 07/04/2018).

17. Agny: the center of neuromarketing technologies, available at: http://agny.ru/ (accessed 07/04/2018).

18. LessWrong: a series of articles by Eliezer Yudkovsky on rational thinking, available at: http://lesswrong.ru/ (accessed 07/04/2018). 